\title{
Division of Child and Adolescent Psychotherapy
}

\author{
소아청소년 정신치료 소모임
}

일시 및 장소: 2016년 2월 17일, 한국정신분석학회 사무실

사례 발표자: 심건의원 김연희 회원(3plus7@hanmail.net)

\section{〈관련자료 출처〉}

Novick KK, Novick J. Working with parents makes therapy work. In: Novick KK, Novick J. Chapter 1. Parent work-introduction and history. Lanham, MD: Jason Aronson;2005. p.1-14.

\section{A Work in Progress}

소아, 청소년의 부모들은 위기의 순간에 좌절, 죄책감, 분노를 느끼면서 찾아와 치료자에게 문제 해결과 면죄부를 원한다. 치료자는 당장 도와주어야 한다는 압박을 받고, 조기 치료 실패와 중단으로 이어진다. 우리는 parent work가 치료의 모든 구 조에 포함되어야 더욱 효과적이라는 것을 발견했다.

\section{The Tasks and Problems of Clinical Work}

Parent work는 정신분석에서 프로이트의 1919년 저작, 안나 프로이트의 1920년대 문헌 등 오랜 역사를 가지고 있지만, 대 부분 비공식적이었다. 누가 작업을 하며 목적이 무엇이고 어떻게 구조화해야 한다는 등 작업의 범위에 대한 합의가 거의 없다.

\section{Parent Work를 방해한 문제점들}

\section{사회적/역사적 요인}

19 세기 후반과 20세기 초반 서양 여성의 역할이 소극적일 수밖에 없고, 양육에서 권력을 가질 수 없었던 점이 영향을 주었 다. 프로이트의 '꼬마 한스' 사례에서 엄마는 욕망의 대상이나 아버지와 경쟁하는 상대로 여겨질 뿐 아이의 성장에 주요한 영향을 주고 있는 존재로 보지 않았고(Oedipus complex), preoedipal mother는 부정되었다.

\section{이론적 요인}

1897년 Freud 유혹가설을 포기하고 외부 현실(부모의 영향을 포함하는)이 아닌 정신 내적인 소망과 욕망을 신경증의 주 요한 결정적 인자로 보는 과감한 전환을 했다. 이러한 전환이 parent work를 상대적으로 방치하게 된 주요 요인이었다.

\section{정치적 요인}

일부 초기 아동 분석가(Von Hug-Hellmuth H)들은 parent work를 둘러싼 문제의 복잡성을 인지하고 있었지만, Melanie Klein과 Anna Freud는 주로 아동 환자에 대한 배타적인 1 대 1 작업 모델을 제시했다.

This is an Open Access article distributed under the terms of the Creative Commons Attribution Non-Commercial License (http://creativecommons.org/licenses/by-nc/3.0) which permits unrestricted non-commercial use, distribution, and reproduction in any medium, provided the original work is properly cited. 


\section{부모에 대한 개인치료}

분리개별화와 관련된 Mahler의 작업은 치료에서 부모를 기본적으로 단절시키는 데 사용되었고 이후 많은 청소년 치료자 와 정신분석 이론에서 청소년과 부모 사이에 거리 두기를 규범으로 했다. 외래 환경에서 작업하는 경우 부모가 받는 정신분 석의 효과를 이상화하거나 과대평가해서 parent work를 간과했다. 아동 분석가들은 부모 역할의 변화가 분석에 의해서 일 어나고, 부모의 병리와 저항을 다루어서 아동치료가 중단되지 않을 것이라 기대하지만 그렇지 않다. 그 이유는

- 첫째, 성인 병리는 종종 부모-아동 관계와 격리되어 있고 치료의 후반부에 다루게 되거나 전혀 다루지 않기도 한다.

- 둘째, 부모와 아동을 동시에 분석하는 Hampstead Clinic의 연구결과에 따르면 부모와 아동의 병리에는 밀접한 상호작 용이 있으나 놀랍게도 부모의 분석에서 아동은 거의 잘 묘사되지 않거니와 parent work로서 분석은 한계가 있다.

- 셋째, 부모-아동의 밀접한 관계는 아동의 잠재적인 발전에 강력한 긍정, 부정의 영향을 줄 수 있기 때문에 직접적으로 다루어져야 한다.

- 넷째, 부모 역할이라는 것 자체가 아동의 치료 측면에서 가장 효율적으로 작용할 수 있으므로 치료에서 부모에게 가장 최선의 기능을 하도록 요구할 수 있다. 문제가 많은 부모라도 아이를 위해서 자신의 어려움을 넘어서는 능력을 발휘할 수 있다.

- 다섯째, 아동이 변화하는 범위와 지속성은 언제나 아동의 성장을 지지하고 변화시키는 부모의 능력에 달려 있다.

\section{Role of Rescue Fantasies in the Clinician-Hostility to Parents}

구원환상은 절망감에 대한 방어로 hostile omnipotent fantasy를 사용하는 것이다. 치료자의 구원환상에 존재하는 부모들 에 대한 무의식적인 공격성은 치료를 어렵게 하는 부모의 방어적인 공격성에 대한 반응일 수 있다. 부모, 특히 엄마와 공감 하기 위해서 아동 분석가는 아동의 첫 번째 대상인 'pregendered' mother에 대한 그들 자신의 무의식적, 원초적인 소망, 공 포, 방어적이고 반응적인 분노를 알아차려야 한다. 
일시 및 장소: 2016년 2월 17일, 한국정신분석학회 사무실

사례 발표자: 동안성병원 유기묵 회원(daebung108@naver.com)

\section{〈관련자료 출처〉}

Novick KK, Novick J. Working with parents makes therapy work. In: Novick KK, Novick J. Chapter 2. Our assumptions when we work with parents. Lanham, MD: Jason Aronson;2005. p.15-22.

\section{부모되기는 정상 성인 발달과정이다}

부모되기는 자기를 넘어서 무엇 또는 누군가를 창조, 돌보고, 보호하고, 양육하고, 사랑하고, 존경하고 즐거움을 얻는 능 력을 의미한다. 인생 주기를 통틀어서 지속되며 부모됨이라는 강력한 청소년 이후의 시기를 포함한다는 것을 강조하고 있다.

\section{부모와 자식은 평생에 걸쳐 복잡한 상호작용을 한다}

내재화된 부모 표상의 성질과 내재화된 부모와의 정신적 관계는 성인기 기능에 지대한 영향을 준다. 예술가들은 이 점을 알고 이런 사실을 중요한 극적 효과로 사용할 줄 안다.

1957년 이래 부모와의 치료를 시작해 온 이후 Erna Furman은 그 풍부함과 복합성의 전개에 있어 절대 무엇에도 뒤지지 않는 부모-아동 관계에 대한 이론을 제시했다. 그녀는 치료에 있어 주된 방해의 원천으로 부모들을 보는 개념에서 부모-아 동 관계를 "두 개의 상호 밀접하게 짜여진 인격들이 다양하고 끊임없이 변하는 무의식적 방법들 속에서 상호 보완하고 있는 복합적 다중 결정적 상호작용”으로 볼 수 있게 해준다.

\section{소아 청소년 치료의 두 가지 목표}

- 전향적 발달의 길로 아동을 회복시키기

- 부모 아동의 관계를 평생 동안의 상호 긍정적 원천으로서 회복시키기

\section{Therapeutic alliance tasks}

부모는 아동의 치료 동안 치료동맹 과업들을 가진다.

- 평가 동안의 부모의 과업은 여러 변화들을 시작하는 것이다.

- 아동의 치료 초기에 부모는 아이가 다른 어른과 같이 있도록 허용하고 육체적 분리를 받아들이는 과업을 가진다.

- 중반기에 아이를 다른 사람과 사적으로 함께 작업하도록 허용하는 것은 아이의 심리적 분리를 통합시키는 것을 의미한다.

- 아이의 발전을 즐기고 승인해 주는 것은 종결기에서 부모의 과업이다.

- 종결기에 부모는 치료를 상실하게 되는 것을 애도하는 작업을 하고 동맹과업 완수를 내재화하고 부모되기 시기에서 발 달을 공고히 하기 위해 작업한다.

- 치료가 종결된 이후에 부모는 아이가 지속적인 성장을 하도록 허용하고 그와 함께 성장한다.

\section{Parental movement from the 'closed' to the 'open' system of self-regulation is the overarching criterion of change}

원천이 무엇이든지 무력감의 경험을 마주하면 모든 사람은 대처하고 나은 기분을 느낄 방법을 찾아야 한다. 이런 적응들 은 건설적이고 창조적일 수 있고 자기 조절의 'open-system'이라고 부르는 것을 만들게 된다. 발달의 어느 단계에서 대안적이 며 동시적으로 개인은 전지전능한 방어들에 기초한 가용한 병리적 해결책들을 가지는데 우리는 이것을 'closed-system'이 라고 묘사했다. 부부 간, 부모 자식 간을 포함한 모든 관계들에서 사랑의 특성과 형태는 이런 두 시스템과 관련된다. 상호 향 상시키는 관계가 생겨나고 open-system functioning과 성장을 만든다. 반면 closed-system functioning은 관계의 피가학적 
형태에 공헌하고 재강화된다. 따라서 우리는 그들의 아동과 closed-system functioning하는 데서 벗어나서 부부 간에 서로, 그리고 아이들과 더 열린 open-system에서 자기 조절과 관계로 가는 움직임을 지향하는 것이 치료의 목표다.

\section{Parent work is substantive and legitimate. It makes use of the full repertoire of psychoanalytic interventions}

우리의 경험에서 부모작업에서 모든 영역의 치료기술을 사용하는 것은 부모들과의 개인치료와 경쟁하거나 방해하지 않 는다. 실제로 양육 문제에 대한 문제로 아동 분석가와 치료 관계를 유지하고 있는 동안 부모작업은 개인치료의 의뢰를 받아 들이도록 유도할 수도 있다. 부모작업은 부모-아동 관계에 초점을 맞추며 부모의 인생에서 다른 사안들은 그것들이 아동과 의 관계에 관련성을 가지는 경우에 한해서만 다루어진다. 따라서 우리는 양육이란 매우 제한되고 집중된 영역에서 제한 없 이 우리의 모든 영역의 기술들을 사용할 수 있다. 심각한 음식 알레르기를 가진 8세 소년인 니콜라스의 부모와의 작업에서 다음과 같이 작업을 하였다.

니콜라스의 부모는 이따금씩 심각해지는 우울병을 겪고 있었다. 그의 다정하고 공감적인 어머니는 쉽게 압도되거나 눈물 을 흘리는 경향이 있었다. 반면 그의 아버지는 흔히 무슨 일에도 적대적인 불안을 표현하곤 했다. 니콜라스는 치료를 시작할 때 많은 두려움을 가진 채로 학교에서는 저성취자며 괴롭힘을 당하고 있었다. 니콜라스가 그가 가진 능력을 제한 없이 사용 하도록 회복시키는 것만을 치료 목표로 삼아 집중하였다면 치료자는 부모를 개인치료에 의뢰하고 부모작업을 최소로 유지 하였을 것이다. 이 부모는 이 시점에서 그런 의뢰에 저항했을 수도 있고 그들은 니콜라스가 치료자와 개별적인 관계를 가지 는 것을 허락하는 것에 불편해 했을 수 있다.

대신에 마음속에 치료의 두 가지 목적을 가지고 분석가는 부모와 작업하면서 아동의 치료를 시작할 수 있었다. 그런 맥락 에서 분석가는 점차 부모의 불안이 니콜라스가 부모의 기분에 가지는 전지전능한 책임감의 감각과 정교하게 얽혀 있으며 그의 신체적 취약성에 대한 감각에 관한 피가학적 관계가 그의 학교 친구들과의 상호작용에서 발생하고 있음을 이해하였다.

부모작업이 깊어짐에 따라 동맹은 강화되었고 마침내 니콜라스의 아버지는 부모 회기에서 그가 아이가 집을 나설 때마다 아들의 목숨에 대해 걱정했으며 가까이 둘 필요가 있었다고 털어놓았다. 분석가는 아버지가 니콜라스의 활동을 제한했고 그의 불안을 줄이기 위한 방편으로 그의 아들을 이용함에 따라 결과적으로 두려움이 발달하게 되었음을 해석하였다. 부모 모두 이 해석에 눈에 띄게 불편해 했으나 마침내 부모작업이 이 문제를 해결하는 것을 도울 수 있고 아버지에 대해 개인치료 를 하는 것이 아버지의 불안의 근원과 기능에 대해 탐색하는 것을 가능하게 한다는 제안을 받아들이게 되었다.

유사하게 그의 어머니를 어떻게 해서든지 행복하게 하려는 니콜라스의 노력은 어머니에게 밝혀지게 되었고 정신치료 의 뢰와 약물치료가 성공적으로 이루어졌다. 부모 양측과의 작업은 니콜라스의 치료 전체 동안 결실 있게 진행되었다. 
일시 및 장소: 2016년 3월 16일, 한국정신분석학회 사무실

사례 발표자: 고양정신병원 최원석 회원(yaho81@naver.com)

\section{〈관련자료 출처〉}

Meeks JE, Bernert W. The fragile alliance: an orientation to psychotherapy of the adolescent. Malabar, FL: Krieger Publishing Company;2001.

청소년기에 대한 시각을 확장시켜 주는 세 가지 차원의 관점은 1) 문화적 기회와 제한의 특별한 역할, 2) 청소년기의 사고 과정의 특성, pregenital 요인과 초기 함입물(introjects), 3) 자아의 합성 역할의 중요성에 대한 인식을 증진시키는 것이다.

정체성에 대해 탐구하는 청소년은 “나는 누구인가?”라고 자문하지 않고 대신 “내 자신을 만들어가기 위해 무엇을 원해야 하며, 내가 무슨 일을 해야 하는가?”에 대한 질문을 한다.

청소년은 finality를 의미하는 위치나 역할을 수행할 수 없는데, 왜냐하면 나중에 청소년이 만들고 싶은 자신이나 청소년 이 해야 되는 일이 잘못된 것으로 판명될 수 있기 때문이다. 청소년기의 타협 해결책은 '시도'라는 웅덩이를 포함하는데, 만 약 물살이 너무 빠르거나, 소용돌이가 너무 깊거나, 또는 결국 자신이 풋내기 선원임을 결정하는 경우에도 밖으로 점프하는 옵션을 사용할 수 있다.

보통의 청소년들은 삶에서 조용히 자신의 실험을 실시하며, 표면적 행동은 잘 수용되는 범위 내에서 대부분 유지되고 내 부적인 투쟁은 심지어 명백하지 않고 예술적 기질의 몇몇 전시로 나타난다. 그러나, 정상 청소년기 내에서도 발달 패턴의 범 위가 있다. 정신치료에 참여하는 청소년들은 매우 다른 그룹이다. 그들에게 있어, 청소년기는 말 그대로 삶과 죽음의 문제이 다. 만약 그들이 개인적인 무결성과 잘 보이기 위한 자신의 개념에 모두 맞는 역할을 찾을 수 없는 경우, 그들은 공연을 거부 한다. 청중들의 박수가 그들에게는 이용되는 느낌이며, 불충분한 보상으로 보인다. 그들은 명령 수행에 있어 얽매여 있지 않 게 된다.

정신치료에 참여하는 청소년들은 일반적으로 세 그룹으로 나뉜다. 한 그룹은 단지 현실적으로 사용할 수 없는 역할이 요 구되었을 때에만 역할을 요구하는 경험과 정서 발달이 비전형적인 젊은이로 구성되어 있다.

\section{Case 1}

치료자에게 단지 어떤 가치 있는 일이 위임된다면 그의 work paralysis가 사라질 것이라고 확신한다고 이야기한 18 세 소 년(가치 있는 작업의 예: 미국 정부의 행정부 구조 조정).

다른 청소년들은 더욱 손상되어, 내적으로 일관성이 없거나 심지어 뚜렷하게 정신병적인 요구와 소원에 직면한다.

\section{Case 2}

300 파운드 이상 체중이 향상된 13세 소년 Paul은 치료자에게 무인도에 절대 군주제를 확립하기 위한 자신의 계획 때문에, 체중을 감량할 이유가 없다고 말했다. 부적절한 정동과 연상의 이완을 보였고, 자신의 망상 제국의 현실을 확신하는 것처럼 보였다.

병원에서 퇴원한 이후 어머니가 식이제한을 시도하자 어머니를 칼로 위협했다. 어머니가 치료자에게 놀라서 전화하였으 나, Paul의 아버지가 “정신의학을 믿지 않았기 때문”에 Paul과 어머니는 치료를 받지 않았다. 5년 후, Paul의 어머니는 치료 자가 Paul에 대해 증언할 수 있는지 전화하였는데, Paul이 다른 나라에서 비행기를 납치한 이후 비행기 피랍 혐의로 재판에 처한 상태였다. Paul의 정신병적 임무는 결국 현실 세계에서 매우 위험한 충동적인 모험에 이르렀고, 그는 법적으로 미쳤다 고 판명되어 5년 더 치료를 받았다. 
문제 청소년의 세 번째 그룹은 치료자에게 그들의 어려움에 대해 설득력 있는 주장을 제시하며, 자신의 재능에 대한 적합 한 수단이 부족하고, 질이 낮음을 탓한다. 사회 제도가 지금까지 완벽하지 않기 때문에, 그들의 주장은 표면적으로 장점이 있으나 자세히 살펴보면, 사회적 결함이 있는 문제를 대부분 받아들이지 않아 이와 유사한 상황에서 현저하게 어려움을 겪 는다.

오늘날의 청소년들 중 지속적이고 합의된 사회적 비판을 하는 이는 거의 없는데 이는 청소년기가 더 이상 성인 세계와의 전투를 하지 않는다는 것을 의미하지 않는다. 그러나, 이때에 전투는 가정에서 더 흔하며, 아마도 정치적인 것보다 더 대인 적인(interpersonal) 것이며, 덜 거슬리는 것이다. 물론 더 심하게 손상된 청소년들은 사회에 대항할 수 있지만 그들의 거부 는 무차별적이고, 분명히 열정적이며, 명백하게 자기 파괴적인 경향이 있다.

치료 초기에, 청소년은 자신의 인생에서 새로운 성인을 부정적인 자아 이미지와 그의 더 비참한 함입물(introjects)을 외재 화할 수 있는 screen으로서 활용하는 경향이 있다. 치료자는 사회적, 문화적, 청소년이 슬퍼하는 가족 악마의 편리한 화신 (embodiment)이 될 수 있다.

치료 이후에, 치료자는 자주 자신이 비현실적으로 상승되고 이상화의 지점을 향한 것을 발견한다. 청소년의 반응이 제대 로 활용하거나 해결되지 않는 경우, 청소년의 감정적인 성장을 방해할 수 있다. 치료자가 성인과 함께 작업하면서 자신을 연 합시키는 관찰 자아(observing ego)는 많은 청소년에서는 제대로 발달하지 못했거나 아직 없다. 노련한 정신치료자는 환자 가 자신 안에서 왜곡의 기원을 localize하고 그들의 가능한 의미를 반영할 때까지 환자가 자신의 의도와 인격을 왜곡하기를 기대한다.

\section{The Adolescents Style of Relating}

청소년기가 시작되면, 젊은이는 자존심에 여러 갈래의 공격을 받기 쉽다. 침입하는 힘은 예측 불가능한 영향과 신체 구성 및 크기의 고르지 못한 급격한 변화, 금지된 충동의 급증, 청소년이 자신의 소중한 부분을 잃고, 그의 부모를 평가 절하하는 자신의 필요를 포함한다. 이 공격에 대한 주관적인 반응은 내면의 손상과 부상에 대한 막연히 불안한 느낌이다. 청소년의 다 른 사람에 대한 애착은 주로 자기애적이다.

\section{Case 3}

억제된 14세 소년이 6개월 동안 치료를 받으면서 자신의 치료자가 결혼한 것에 놀라움을 표시했다. "당신은 더 '성적으로 자유분방한(swinger)' 유형처럼 보이는 군요”라고 그는 외쳤다. 치료자는 청소년과의 접촉 내내 명확히 보이는 결혼 반지를 착용했다. 같은 치료자는 다른 요구를 가진 청소년에 의해 절망적으로 구식이며, 명백히 고지식하다고 비난받았다.

청소년들은 다른 사람들에게 강렬하지만 여전히 순식간에 피상적인 애착을 종종 보여준다. 청소년은 검색하는 특성을 가 지고, 자주 변덕스럽게 묘사되며, 자신의 내면의 혼란에 대한 외부 해결책을 약속하는 새로운 개체에서 실제 또는 환상의 자 질에 대해 반응한다. 모든 해결책에 대한 기대로 인해 자기 자신과 애착관계에 있는 사람들을 환멸한다.

\section{The Thought of the Adolescent}

형식적 조작기(formal operation)의 능력이 초기 청소년기에 나타나며 처음으로 논리적으로 자신의 생각을 조작할 수 있 게 한다. 형식적 조작기의 출현은 다양한 사실, 문제점 및 아이디어 사이의 상호 관계의 일반적인 이론의 구성을 허용한다. 청소년은 자신의 세계에서 추상적인 사고에 대해 이 능력을 적용하고 주위에 현실을 재편하기 위한 도구로서의 강점과 능 력을 지나치게 강조한다. 임상적으로, 이러한 경향은 단지 그것에 대해 생각하는 것에 의해 자신의 세계를 변경하는 청소년 의 능력의 거대한 과대평가와 생각의 전능함에 대한 믿음으로 나타난다. 이것은 종종 성인에서 조바심의 감각으로 나타나 며, 꾸물대는 것처럼 보이고, 논리적 접근에 의해 쉽게 해결될 수 있는 문제를 불필요하게 복잡하게 하는 것처럼 보인다. 인 지적 영역의 이러한 발달은 청소년기 동안 자기애의 감정적인 경향을 강화시킨다. 청소년이 생각을 조작하는 데 있어 새롭 
게 발달된 기술을 활용하는 것과 관련된 영역은 이데올로기의 논의이다. 청소년은 어떤 삶의 관점에서 책임감을 향해 투쟁 하며 이로 인해 존재의 의미와 생활방식에 대해 생각하고 이야기하는 데 상당한 시간을 소비한다.

\section{The Adolescent and Society}

성인의 청소년의 관점은 양가 감정의 고유 요소가 포함된 조직화된 사회이다. 청소년은 무엇보다도 연역적인 사상가로 사회에 대한 호기심은 해당 기관, 운영 방법 및 보상 시스템의 활성 연구로 반드시 이어지는 것은 아니다. 인간의 행동에 대 한 지식이 부족하며, 유토피아적인 전망을 가지고 있기 때문에, 역사적 관점에서 제한된 흥미를 발전시킬 수 있다. 광범위한 판타지, 추측, 그리고 이론화에 몰두할 가능성이 높다. 
일시 및 장소: 2016년 3월 16일, 한국정신분석학회 사무실

사례 발표자: 밝은미래 정신건강의학과 이현정 회원(aranh@hanmail.net)

\section{〈관련자료 출처〉}

Meeks JE, Bernert W. The fragile alliance: an orientation to psychotherapy of the adolescent. Malabar, FL: Krieger Publishing Company;2001.

\section{Adolescent Adaptation}

청소년에 의해 사용되는 적응 기술과 자아 방어가 이 나이에만 고유한 것은 아니나 강조되는 일부의 특징적 패턴들이 있 다. 친구가 없거나 어른과의 관계를 더 선호하는 청소년은 치료자로 하여금 감정적 갈등의 가능성에 대해 경보를 울리는 좋 은 예시의 패턴이다. 또래와 어울리는 것은 청소년의 가장 보편적 적응 기술이다. 또래를 갈구하는 것은 최소한 네 가지의 압박과 관련되어 있다.

1) 자기애적 지지에 대한 내적 욕구이다. 그룹에 속함으로써 수용되는 느낌을 제공하는 것뿐만 아니라 죄책감을 공유한 다. 성적, 공격적 욕구에 의해 격노한 초자아가 자존감에 미치는 막대한 영향을 감소시키고, 지지한다.

2) 궁극적인 독립과 성숙한 사랑을 준비하기 위해 부모와의 의존적, 무의식적 에로틱한 유대를 느슨하게 해야만 하겠다는 강한 느낌을 받는다. 또래와의 동료애는 이 작별의 과정이 수반하는 지지의 상실을 일부 대체할 수 있다.

3) 편안하고 견딜만한 개인의 정체성의 결여이다. 견딜만한 자기감 sense of self를 정의하기 위한 내적 갈등에서 오는 불 안으로 인해, 청소년은 ‘나’가 되어야 하는 공포스러움보다 ‘우리' 안에 속해 있는 안전한 느낌을 더 선호하게 된다.

4) 넓은 범위에서 그룹 형성은 사회적 현실에 의해 청소년에게 강요된다.

\section{The Power of Words}

청소년의 수다는 종종 끊임없이 몰아오는 특성을 보이는데 지식화의 방어기제로 사용되기 때문이다. 때로는 자기성찰적 일 때도 있다. 독백은 자신의 갈등과 관련된 감정으로부터 얼마간의 거리를 유지하게 해서 갈등에 대한 정확한 통찰을 담고 있기도 하다. 그럼에도 Blos가 1963년 'On Adolescence'에 지적한 것처럼 지식화의 방어기제는 본능에 대한 인내력을 높여 주므로 청소년기에 대체로 긍정적인 긴급조치이다. 종종 많은 말들은 청소년 자신의 개인적 감정과 명백히 연관되어 있기 보다는 철학적 토론의 형태를 띤다.

사례: 매우 불만족스러운 13세 청소년이 치료 초기 몇 시간 동안 치료자를 포함한 어른 세상은 위선자들뿐이라고 비난을 쏟아 냈다. 치료 관계가 수립되고 얼마 후 여자 청소년은 자신의 위험한 성적 도발에 대해 이야기하고 싶어 했다. "그 모든 위선자들에 대해 언성을 높여 왔지만 내가 그중 최고인 것 같아요." 심층적 수준에서는 자신의 엄격한 소아기적 초자아와 이질적이게 느껴지는 성적 느낌 사이의 불일치를 의미하는 듯 하다.

\section{Misdirection}

마술사들은 실제 트릭을 일으키는 미묘한 움직임보다 크고 명백한 움직임을 만들어 관객의 시선을 분산시켰다. 마술의 이 테크닉을 misdirection이라 부른다.

청소년은 종종 다른 사람들이 주목하거나 눈치채게 할 수 없도록, 태도나 감정을 숨기려고 주의를 분산시키는 전략을 많 이 쓰는 듯하다. 이 방법은 특히 숨겨야 하는 감정이 고요하고 온화한 것인 경우에 더욱 효과적이다. Misdirection이라고 명 명한 청소년의 이 방어적 기술은 동시에 발생하는 보다 받아들이기 어려운 감정을 자신과 타인으로부터 숨기기 위해 사용 하는 감정의 과장된 표현이다. 이 방식의 작동은 청소년이 어째서 한 가지 감정, 특히 분노를 그토록 극단적으로 표현하는지 
설명해 준다. 이는 Anna Freud가 말한 '정동의 전환’과 다소 연관되어 있다. 정동의 전환이란 청소년이 부모에 대한 자신의 감정을 격한 증오로 전환시켜 부모에 대한 긍정적 애착의 감정으로 인해 생기는 갈등과 불안을 회피하고자 하는 시도를 의 미한다.

\section{Apollo Versus Dionysus}

청소년은 자신의 초자아 갈등에 적응하고자 하는 다양한 시도를 한다. 이는 성인 관찰자에게는 종종 혼란을 불러일으키 곤 한다.

사례: 15세 소녀 Pattie는 반항적이고 성적으로 문란한 행동이 도가 지나쳐 자포자기한 부모에 의해 정신과 병동에 입원하였다. 그녀는 병동에서도 조숙한 유혹적 차림새로 행진하고 다녔다. 치료 세 번째 시간에 간호사의 눈을 피해 아주 짧은 스커트에 길이가 짧고 몸의 윤곽이 드러나는 하늘하늘한 블라우스를 입고 나타나 치료자의 눈앞에서 자신의 엉덩이에 손을 얹고 유혹적 몸짓으로 빙그르르 돌기도 했다. 치료자는 평정심을 유지한 채 Pattie를 오래 응시한 뒤 말하였다. "넌 비밀스럽게 네 자신을 창녀인 것처럼 느끼고 있는 것 같아. 사는 데 아주 안 좋은 방법이 분명하다고 생각해. 네가 왜 네 자신을 그렇게 만드는지 한번 예기해 보면 어떨 까?"라고 하자 Pattie는 갑자기 울음을 터뜨리고 욕을 하고 치료실을 나가 버렸다. 이후 병동에서 대담한 노출 행위는 점차 잦아들 었고 병동 간호사에게 치료자가 아주 바보 같은 의사는 아니라고 인정하는 말도 했다. 치료가 진전되면서 Pattie의 도를 넘는 비행 은 엄격한 초자아를 부인하고 빠져나가고자 하는 시도이자 동시에 타인으로 하여금 자신의 행동을 통제하도록 만드는 무의식적으 로 계산된 노력이었음이 분명해졌다.

비슷한 사례는 아주 많다. 빈약한 자아구조와 충동조절 결핍이 있는 많은 청소년은 편안하고 정연하게 충동을 표현하는 것을 용납치 않는 유아적 초자아에 속박되어 무참히 두들겨 맞는다. 이런 청소년들은 쾌락과 자기 파괴적이며 자기 처벌적 인 극단을 연결할 때만 만족을 허용한다.

\section{Ghosts, Goblins, and Things That Go Bump in the Night}

많은 청소년들은 초자연적인 것에 강한 관심을 보인다. 보통 이런 관심은 불쾌하거나 무서운 것은 아닌 듯하다. 장난스러 운 방식이나 친구들끼리 '귀신의 집'을 방문하는 식의 놀이의 기초가 되기도 한다. 천문학이나 주술 등도 청소년에게는 큰 관심사이다.

미신적 관심사의 대부분은 죽음과 불멸에 대한 의문과 관련되어 있다. 죽음에 대한 공포를 아주 사실적일 뿐만 아니라 곧 닥치기라도 할 것처럼 느끼고 있다는 인상을 자주 준다. 그러나 대부분 일반적 청소년들은 역공포적 방법(공포스러운 상황 을 스스로 찾는)으로 이런 공포를 다스린다.

청소년의 오컬트적 성향에는 두 가지 요소가 있다. 첫째는 청소년이 가지는 사고의 전지전능함에 대한 믿음을 반영하는 것으로 현실성은 느슨해지고 마술적 사고가 쉽게 수용된다. 둘째는 자신의 부모 및 소아기의 여러 측면을 포기하고자 하는 노력의 일환이다. 심리적 관점에서 보자면 죽음과 애도는 청소년 자기 경험의 즉각적 부분인 것이다. 청소년의 가장 큰 두려 움은 두려움 그 자체이기 때문에 그들은 때로는 기꺼이 그 괴물을 끌어안아 두려움을 삼킨 뒤 승리를 위해 다시 꺼낸다. 